\title{
Spiritual, Moral and Ethical Dilemmata for Healthcare Professionals During Covid-19 Times
}

\author{
Santosh K. Chaturvedi
}

Received: 7 October 2020/ Accepted: 9 October 2020/Published online: 27 October 2020

(C) Springer Nature India Private Limited 2020

Ethical dilemmas and moral dilemmas have gripped the healthcare situations related to Covid-19. With almost all attention being focused on this pandemic, other health conditions are being ignored and neglected. Healthcare professionals in general, and medical doctors in particular, have to deal with such situations. Healthcare leaders, implying, governments, ministers, administrators and authorities have been focusing on covid-19 and the prevention of its spread by strict and repeated lockdowns, including curtailing or stopping routine healthcare provision to chronic medical disorders, immunisation, dental care, and all non-emergency medical care [1]. This has led to a unique experience among health care professionals, specially doctors and nurses, arising from their predicament. It is difficult to coin a term for such an experience which seems a mix of moral, ethical and spiritual distress and dilemmas.

The Sanskrit word 'kim kartavya vimuda' describes this predicament of doctors-confusion about what their duty is and what they should do; save one life at the cost of losing another! [2] Is it their duty to follow the instructions or orders from their health leaders and systems or listen to the voice of their conscience? If they follow the directions from their health leaders,

S. K. Chaturvedi ( $\square)$

National Institute of Mental Health and Neurosciences,

Bangalore, India

e-mail: skchatur@gmail.com they are consigned to live with the guilt of not doing their duty lifelong.

The features of this phenomenon are characterised by the following in relation to healthcare delivery and related matters. These have been experienced and reported by many of our colleagues facing this predicament. The features are a sense of confusion about what is right and what is wrong, questioning about one's duty and role in the situation, questioning one's purpose in life and work, feelings of frustration, feeling demoralized and what is expected from them by the system, ruminations about the conflict and dilemma, helplessness about what to do, a lack of motivation, a sense of incompleteness of one's existence, a sense of loss of meaning in the given circumstances, a sense of fatigue and burnout, indecisiveness and other experiences which are difficult to put in words.

The ethical dilemma is the compromised autonomy of the healthcare worker, their inability to do what they think is right and justified medically. The principles of 'do no harm' and justice are also ignored as potential harm is done the majority of public suffering from common non communicable diseases like chronic mental illnesses, hypertension, cardiovascular disorders, diabetes mellitus, arthritis, mental, neurological and neurodevelopmental disorders, and even palliative care for terminally ill cancer patients $[3,4]$. In the pre covid times such patients were all advised to do regular physical activity, go for a walk or a swim, or 
regular outdoor exercises in order to improve their respiratory and cardiac functions and attaining wellbeing. All these were prohibited during the lockdown, besides children being deprived of their immunisations due to the closure of hospitals for all medical conditions other than covid related conditions or other emergencies.

There is a conflict between what is medically and clinically right versus what is expected by the system. The medical doctor is trained to provide medical care at times of need, but in the current scenario, the professional has to stop such services for safety of self and others, but at the cost of neglecting other persons suffering and ignoring their needs. This questions the values and compassion in the professional.

This phenomenon reflects spiritual dilemma rather than moral or ethical dilemma. Moral injury has been described as a similar experience [5]. However, this phenomenon questions the professional, whether he/ she is performing the duty expected from them. The professional questions and introspects on what are their duties in the prevailing circumstances? This seems to be arising from the perception of the pandemic in a concrete way [black or white] rather than a compassionate view [life is a lot of grey]! Some deaths [due to covid-19] are more important than others [other medical causes], and need to be prevented. Is it really not possible to save every life?

Despite these dilemmas, the submissions to the journal have been pouring in. This issue has two commentaries on challenges faced in the field of psychosocial rehabilitation in London, UK and Lahore, Pakistan. Couple of interesting methods useful for recovery and rehabilitation included in this issue pertain to street football and use of service dogs. The international representation of research contributions continue as this issue is quite global with articles from Ghana, Ethiopia, Norway, Canada, Pakistan, United Kingdom, United States of America and India. Articles from India are interesting perspectives on the use of domestic skills in rehabilitation, challenges of finding placements for the homeless mentally ill and reintegrating them in the community and the perceptions of nursing students about psychosocial rehabilitation.

The pandemic has enforced the new normal in life and hopefully a new normal will be accepted in the care of persons with psychiatric disorders including their rehabilitation [6]. The concepts of psychosocial rehabilitation and recovery will adapt the new normal.

\section{References}

1. Andrade C. Covid-19, Humanitarian and health care crisis in third world country. J Clin Psychiatry. 2020;81:20com13383.

2. Chaturvedi SK, Pai NM, Singh N, Jha A. Embracing uncertainty during COVID-19 times: psychiatry training, research, and practices in an institute. Indian $\mathrm{J}$ Soc Psychiatry. 2020;36:151-3.

3. Chaturvedi SK. Covid-19, coronavirus and mental health rehabilitation at times of crisis. J Psychosoc Rehabil Ment Health. 2020a; 7:1-2.

4. Pramesh CS, Badve RA. Cancer management in India during Covid 19. N Engl J Med. 2020. https://doi.org/10.1056/ NEJMc2011595.

5. Greenberg N, Docherty M, Gnanapragasam S, Wessely S. Managing mental health challenges faced by healthcare workers during covid-19 pandemic. BMJ (Clin Res Ed). 2020;368:m1211. https://doi.org/10.1136/bmj.m1211.

6. Chaturvedi SK. Covid-19 related psychiatric disorders and the new psychosocial rehabilitation. J Psychosoc Rehabil Ment Health. 2020b; 7:103-5.

Publisher's Note Springer Nature remains neutral with regard to jurisdictional claims in published maps and institutional affiliations. 